\title{
Use of Multi-Criteria Decision Aid to Evaluate the Performance of Trade Marketing Activities of a Brazilian Industry
}

\author{
André Andrade Longaray ${ }^{1, *} \&$ Leonardo Ensslin ${ }^{2}$ \\ ${ }^{1}$ Federal University of Rio Grande (FURG), Rio Grande, Brazil \\ ${ }^{2}$ Southern University of Santa Catarina (UNISUL), Florianopolis, Brazil \\ *Corresponding author: Economic Sciences' Administrative and Accounting Institute - ICEAC, Federal University \\ of Rio Grande (FURG), CEP: 96203-900, Rio Grande, Brazil. Tel: 55-519-354-4547. E-mail: \\ longaray@yahoo.com.br
}

Received: January 26, 2015

Accepted: February 20, 2015 Online Published: March 29, 2015

doi:10.5430/mos.v2n2p15

URL: http://dx.doi.org/10.5430/mos.v2n2p15

\begin{abstract}
This paper detail the use of the Multi-Criteria Decision Aiding methodology model as an instrument of intervention in a case study conducted in a Brazilian industrial company. A customised evaluation model was built interactively by interviewing decision makers to identify, organise, measure, and integrate those factors considered necessary and sufficient for the management of trade marketing. The constructed model enables executives to incorporate unique aspects of the company and the environment, expanding the possibilities for performance evaluation of trade marketing in the organisation.
\end{abstract}

Keywords: $M C D A$; decision aid; trade marketing

\section{Introduction}

Brazilian industrial production has grown significantly in recent years. Data from the Brazilian Institute of Geography and Statistics (IBGE) indicate that industrial production grew 1.8\% in the period between August 2010 and August 2011 (IBGE, 2013). In the analysis, sixteen of the twenty-seven sectors of the analysed industries presented an increase in production. Among these, the pharmaceutical sector highly influenced the final result, showing a cumulative growth of 3.9\% (IBGE, 2013).

Today, Brazil is the world's seventh largest pharmaceutical market, and is expected to be the fifth largest before 2015 . This is due both to the expansion of social class $\mathrm{C}$, which represents $42 \%$ of the consumers of this sector in the country, and to the increase in exports, which in 2010 reached 1.7 billion dollars (Abradilan, 2013).

The current national pharmaceutical market outlook is extremely favourable, but at the same time, it presents a number of challenges to be overcome. Among them are the increased competition caused by the influx of laboratories from other countries, the need to constantly adapt to new rules of health regulatory bodies, and the change in the profile of consumers, who have become more demanding as their options have increased.

In this scenario, characterised by dynamism and oversupply, Brazilian pharmaceutical companies have adopted new strategies in the pursuit of greater competitiveness. Given the range of possibilities, a significant number of companies in this market segment have chosen to incorporate trade marketing into their management practices.

Trade marketing represents the set of efforts along the distribution channels to enhance the relationship between brand, points of purchase and consumers. The main objectives are to strengthen the brand, to create interest using the commercialisation of sales channels, and to attract the preference of the targeted consumers.

Considered a relatively new discipline, which first appeared in the early 1990s, trade marketing is still developing as a management tool. One of the emergent questions relates to the ways by which trade marketing activities can be measured, apart from the concurrent activities of sales and marketing departments, in order to demonstrate its contributions to the company.

While marketing actions can be measured by the market value of the brand, the number of sales channels, and the 
number of the product's consumers; and sales actions can be measured by the actual amount of commercialised products and the market share of the brand, there are no clear ways to measure the results of trade marketing activities, because they are based on cultivating relationships with distributors, points of purchase, and customers.

Within this context, the present study aims at developing a model to assist the managers from a pharmaceutical company in the identification, implementation, and measurement of criteria that allow the evaluation of the performance of trade marketing department activities. Taking into consideration the complexity of the situation, the multiple variables covered, the conflicting interests involved, and the need to help managers to understand the context, the Multi-criteria Decision Aiding - Constructivist Methodology (MCDA-C) is used for its potential to deal with these contexts. (De Moraes, Garcia, Ensslin, Da Conceição \& De Carvalho, 2010; Lacerda, L. Ensslin \& S. Ensslin, 2011a; Lacerda, L. Ensslin \& S. Ensslin, 2011b; Rosa, L. Ensslin, S. Ensslin \& Lunkes, 2012).

This article is organised into six sections. Following this introductory section, section 2 discusses the concept of trade marketing and the issue of its indicators, and section 3 shows the Multi-Criteria Decision Aiding - Constructivist methodology. Further, section 4 presents the methodological procedures of the research. Section 5 describes the construction of the evaluation model of the case study and, finally, section 6 addresses the final remarks of the research.

\section{Trade Marketing and the Issue of Indicators}

The concept of trade marketing first appeared in the last decade of the 20th century, promoted by the reversal of the consumption trends most prevalent until that time. Technological advances began to dissolve traditional boundaries between markets, causing the situation to change from one in which demand was greater than supply, to a situation of excessive demand (Huber, Dippold \& Forsthofer, 2012).

Within a scenario where the visibility of both products and services offered, the speed in the logistics process, and the reduction of operating costs have become vital for businesses survival in the new economy, the importance of distribution channels - distributors, wholesalers and retailers - also increased.

Thus, the expression 'trade marketing' was born. First employed by the North-American company Colgate Palmolive, it refers to the integration of the functions of the company's sales and marketing departments, and is aimed at strengthening relationships between the manufacturer and its distributors.

The goal of this integration was to establish procedures to recognise the habits and needs of the consumers from a particular distribution channel and to outline strategies to turn that clientele into potential buyers of the brand. As a result, new initiatives concerning price, location, display, innovation, packaging, assortment, and merchandising were developed (Sponton, 2008).

Initial attempts to implement trade marketing tactics first took the form of commercial sales assistants dedicated to key business customers. This tactic soon progressed to the appointment of marketing executives who would have the responsibility of managing the performance of their key customers. Today, a significant number of organisations have chosen to designate a trade marketing department (Almeida, Penna, Silva \& Freitas, 2012).

Such a development is justified, especially in Brazil, by the growth of the retail distribution channel, or as it is usually called, the point of purchase (POP). According to Silva Neto, Macedo-Soares and Pitassi (2011), a survey conducted by POPAI - Point of Purchase Advertising International - in 2007 revealed that in Brazil, 85\% of purchases are decided at the point of purchase, while in the rest of the world this percentage is no higher than $7 \%$.

A controversial issue, however, concerns the evaluation of the contribution of the trade marketing department to the company's results. Metrics are outlined and traditionally used for sales and marketing areas (Kotler, Hermawan, \& Iwan, 2013), but the same does not happen with the trade marketing area.

Recent studies have addressed the difficulty of establishing proper indicators for trade marketing actions (Almeida et al., 2012; Alvarez, 2008; Castillo, 2000; Labajo \& Cuesta, 2004; Silva Neto et al., 2011) that do not overlap those already used to evaluate the results of marketing and sales departments (Cobra \& Talarico, 2008; Motta, Santos \& Serralvo, 2008).

In a study in the pharmaceutical sector, a segment of which the subject company of this research is also a part, Huber et al. (2012) noticed the lack of standard indicators to assess over-the-counter (OTC) medicine sales performance in a company from the pharmaceutical sector.

Following the previous research, this study uses the multi-criteria methodology for decision aiding to construct a model to evaluate the performance of trade marketing activities in a pharmaceutical company with a significant 
number of points of purchase throughout Brazil.

\section{Multi-Criteria Decision Aiding-Constructivist Methodology}

The Multi-criteria Decision Aiding - Constructivist methodology (MCDA-C) is an approach derived from the European school of decision (Roy, 1996). It uses constructivism in order to provide understanding and learning about the decision context, and methods of mathematical aggregation of criteria through synthesis subordination to convert qualitative judgments into quantitative ones, synthesising the multiplicity of criteria into a general equation (Roy, 2005).

Constructivism assumes that a person responds to external stimuli to build and organise his own knowledge. The events are real, but the interpretation that is given to them is highly subjective, thus varying from person to person. Therefore, a particular event can be a problem for one person or an opportunity for another (Roy, 2005).

Thus, in the constructivist MCDA, researchers encourage decision makers to actively participate in problem determination and the identification of its causes, as well as in the formulation of possible ways of dealing with the situation perceived as problematic. It is a learning process in which the interaction between researcher and decision maker facilitates a structured approach to problems (Rosenhead, 1989). The practical result is criteria identification, the establishment of a hierarchical structure of values, and the formulation of recommendations (Bana E Costa \& Vansnick, 1995; Longaray, Ensslin \& Mackness, 2005; Bana E Costa, Lopez \& Baets, 2012a).

As for the mathematical method used, the approach of subordination of synthesis, over-classification, or even outranking comes from the French school of decision (Roy, 1996). It establishes a subordinate relationship between the possible actions for the decision by means of thresholds. Such thresholds serve to reduce the difficulty usually found by the decision maker to apply precise numerical values to his preferences (Roy, 2010).

Some examples of over-classification methods are: ELECTRE - Elimination et Choix Traduisant Réalité, created by Roy (1996), which uses weight criteria for the construction of agreement and disagreement matrices, compared with pseudo-criteria through nebulous hierarchical relationships, considering aspects of acceptance, rejection, or estimation of the credibility of the information; PROMETHEE - Preference Ranking Method Organisation for Enrichment Evaluations - which builds a partial pre-ordering of alternatives, using two points of hierarchy, a positive, which shows how an alternative excels over the other, and a negative, which shows how this alternative is overwhelmed by other; and MACBETH-Measuring Attractiveness by a Categorical Based Evaluation Technique - which allows the transformation of ordinal scales to cardinal scales, based on absolute judgments about the difference of attractiveness between two alternatives (Ensslin, Montibeller \& Noronha, 2001).

To implement the process of decision aiding, Ensslin, Giffhorn, Ensslin, Petri and Vianna, (2010), Roy (1996, 2005), and Galves (2005), state that the use of the constructivist MCDA approach has to follow three stages: structuring, evaluation, and recommendations (Montibeller, Ackermann, Belton \& Ensslin, 2001; Montibeller, Belton, Ackermann \& Ensslin, 2008; De Moraes et al., 2010; Tasca, L. Ensslin, S. Ensslin \& Alves, 2010; Della Bruna, L. Ensslin \& S. Ensslin, 2011; Lacerda, L. Ensslin \& S. Ensslin, 2011a; Lacerda, L. Ensslin \& S. Ensslin, 2011b; Rosa et al., 2012; Longaray, Ensslin \& Mackness, 2014).

\subsection{Structuring Stage}

The structuring stage deals with the formulation of the problem and seeks to identify, characterise, and organise the factors considered relevant in the process of decision aiding by the decision maker(s). It occurs in an interactive and dynamic way, stimulating debate and learning (Bana E Costa, 1993; Roy, 2005; Bana E Costa et.al., 2012a).

In this process, the decision makers are to identify a set of criteria that allow the comparison among themselves of different performance levels. According to Roy (2010), the set of criteria has to satisfy the conditions of exhaustiveness (description of the problem taking into account all relevant aspects), cohesiveness (definition of minimisation and maximisation criteria), and non-redundancy (exclusion of criteria that assess features already analysed by another criterion).

In order to facilitate the process of understanding and organisation of the decision context, a soft method of problem structuring is employed at this stage (Rosenhead, 1989; Montibeller et al., 2001; Montibeller, et al., 2008; De Moraes et al., 2010; Tasca, et al., 2010; Della Bruna, et, al., 2011; Longaray et al, 2014). Once identified, the criteria should be organised hierarchically or in a tree structure, in which the highest level of a criterion is divided into more detailed levels.

At the lowest hierarchical level of each criterion, there is a descriptor. A descriptor is an ordinal scale that represents 
the possible levels of impact in which the performance of a possible potential action can be evaluated by a certain criterion according to the preferences of the decision makers (Roy, 2010). Every descriptor has to have, among its levels of impact, two reference levels: a level called Neutral, which corresponds to the performance level below that which the decision maker considers compromising performance for each criterion, and a level called Good, related to the performance level above that which the decision maker considers excellent. Between Neutral and Good, the performance is considered normal or aligned with the market (Montibeller, et al., 2008; De Moraes et al., 2010; Tasca, et al., 2010; Della Bruna, et, al., 2011; Lacerda et al., 2011a; Lacerda et al., 2011b; Rosa et al., 2012; Longaray et al, 2014).

\subsection{Evaluation Stage}

At the evaluation stage of an MCDA-C model, an mathematical method of synthesis aggregation model is applied, beginning with the construction of ordinal scale of local preference of the criteria (preference relationships among levels of a descriptor), followed by the transformation of these scales into ratio scales and its references performance levels (Montibeller et al, 2001; Montibeller, et al., 2008; De Moraes et al., 2010; Tasca, et al., 2010; Della Bruna, et, al., 2011; Lacerda et al., 2011a; Lacerda et al., 2011b; Rosa et al., 2012; Longaray et al, 2014) the determination of rates of compensation among criteria (preference relationships among criteria in the same hierarchical level), and the identification of the performance profile of potential actions (the aggregation of all levels of all criteria in an additive model) (Roy, 2010).

By establishing all preference relationships of the model, it is possible to measure the performance of a particular potential action (an alternative) both locally (performance in one criterion) and globally (performance in all criteria).

In the implementation of the process for decision aiding described in this article, the MACBETH method - Measuring Attractiveness by a Categorical Based Evaluation Technique was used (Bana E Costa \& Vansnick, 1995; Bana E Costa et al., 2012a; Bana E costa, De Corte \& Vansnick, 2012b). In MACBETH, levels of preferences are assigned among the criteria by comparison, using pairs of alternatives. Given two alternatives, the decision maker should indicate the most attractive one and the degree of this attractiveness on a semantic scale corresponding to an ordinal scale $(0 \equiv$ indifferent, $1 \equiv$ very weak difference of attractiveness, $2 \equiv$ weak difference of attractiveness, $3 \equiv$ moderate difference of attractiveness, 4 इ strong difference of attractiveness, $5 \equiv$ very strong difference of attractiveness, and $6 \equiv$ extreme difference of attractiveness).

Note that the numbers on the scale have no mathematical meaning. They are attributed to the pair of alternatives as semantic indicators of the category of difference of attractiveness (Ensslin et al., 2010; Roy, 2010).

From a mathematical perspective, the MACBETH method consists of four problems of minimisation (Mc) of linear programming (LPP), sequentially solved (Bana E Costa \& Vansnick, 1995, Bana E Costa, De Corte \& Vansnick, 2005): LPP1 - Problem Mc1: performs the analysis of cardinal consistency, LPP2 - Problem Mc2: responsible for the construction of the cardinal value scale, and LPP3 and LPP4 - Problems Mc3 and Mc4: reveal sources of inconsistency (Bana E Costa et al., 2012b).

The mathematical relationships can be obtained with the M-MACBETH software, which implements the method computationally. There, the analyses of the decision maker's judgment are made. Using linear programming, a grading scale is suggested, as well as the intervals by which it can vary without making the problem inconsistent. When the processing of the ordinal scales (descriptors) into cardinal scales occurs, M-MACBETH allows the fixation of intervals between Neutral (0) and Good (100) levels, besides bringing about the normalisation of the scale (Bana E costa et al., 2012b).

With respect to the determination of compensation rates of the model (scale constants), M- MACBETH employs the same pair-wise comparison procedure. It should be noted that in the preference relationships among criteria, it is necessary to conduct the ordering of possible actions (Ai) that impact these criteria and to include a fictitious action (A0) in the matrix, before proceeding with the cardinalisation of the criteria (Bana E Costa \& Vansnick, 1995).

One possible way of ordering the criteria is by using the matrix by Roberts (1979). To fill the matrix columns, possible actions that influence the same hierarchical level criteria are simulated, and the decision maker is asked to assign the value ' 1 ' to an action that prevails over others and the value ' 0 ' to an action that is dominated by others. The sum of each line indicates the sequence of actions, according to the decision maker's preferences (Ensslin et al., 2010).

With the determination of the criteria, local preference scales and the compensation rates among these criteria, it is possible to proceed to the transformation of the model of multiple criteria into a single criterion model (global evaluation) (Bana E Costa et al., 2005). 


\subsection{Recommendations Stage}

The recommendations stage of constructivist MCDA aims to support the decision maker in the use of the constructed model through the process of decision aiding. As the employed approach is constructivist, it does not intend to prescribe guidelines, instead only supporting the decision maker in the construction (development) and analysis of possible alternatives and the understanding of its consequences. The implementation of this process can occur in several ways. Among them, Tasca, et al. (2010), De Moraes et al. (2010), Ensslin et al. (2010), Della Bruna et al. (2011) and Lacerda et al. (2011a) suggest the identification of the performance of each cardinal scale to understand the specific performance according to a certain criterion; the establishment of different strategies to identify the impact on the global evaluation of the performance; the analysis of cost versus benefit in the implementation of a strategy; the establishment of priorities in the strategies and actions that are intended to be implanted through the objectives with a greater degree of contribution (rates of compensation); and the performance evaluation at each level (strategic, tactical and operational).

\section{Methodological Procedures of the Research}

This section discusses the methodological design of the research and classifies the work as to its purpose, nature, source of data collection, search logic, methodological approach and the intervention instrument employed.

Regarding its purpose, the research is classified as an exploratory study. According to Gil (2002), the main objective of exploratory studies is to develop ideas and to lead to relatively systematic procedures for obtaining empirical observations, as well as to enable the identification of the relationships between the studied phenomena. This perspective is consistent with the objectives of this research.

The overall objective is to build a customised model to evaluate the performance of the trade marketing department of a pharmaceutical company focused on promoting organisational competitiveness. The specific objectives for the execution of this research are: to describe actors, especially decision-makers, on behalf of whom certain values and preferences will be determined; to identify the criteria that meet the goals of the company's trade marketing efforts; to formulate a hierarchical structure of criteria; to construct ordinal scales for each criterion; to transform ordinal scales into cardinal scales; to establish rates of compensation among the criteria; to construct the criteria aggregation model; to represent the performance profile of possible actions on the constructed model; and to identify and analyse elements that warrant action for improvement.

The nature of this research is described as a case study. The case study was conducted at a large Brazilian pharmaceutical company located in the state of Rio Grande do Sul and which operates in the segments of OTC (over the counter) medicines, herbal medicines, cosmetics, and prescription medicines. The company has a portfolio of over 50 products, 100 presentations, and a network of 40 distributors reaching 40,000 points of purchase throughout Brazil. The company's turnover was approximately $\mathrm{R} \$ 62$ million in 2011. It employs around 1,300 workers.

As sources of data collection, this study used interviews, document analysis, and bibliographic search (Gil, 2002). Unstructured interviews were conducted to obtain primary data and a survey of documents and bibliographic search was done as a source of secondary data.

The search logic adopted was inductive and deductive. It is inductive in the structuring stage of the model, which does not presuppose the existence of principles, but of facts and observations resulting from insertion into reality. It assumes a deductive approach in the evaluation stage, since it is from the constructed model that particular conclusions are established (Gil, 2002). Finally, the logic is inductive in the development of the recommendations stage, since the analyses are based on the understanding gained throughout the development of the entire model.

The methodological approach of the study is quali-quantitative. Gil (2002) advocates the idea of combining qualitative and quantitative methods in order to provide a richer contextual basis for the interpretation and validation of research results. From this point of view, the present study is quantitative at the evaluation stage and qualitative in the structuring and development of recommendations stages.

The intervention instrument employed in the study is the constructivist MCDA. This methodology for decision aiding is used because of its ability to provide conditions for the identification, implementation, and measurement of the criteria that represent the perception of the decision makers about the possibilities of evaluating the performance of trade marketing activities of the company. It also enables the incorporation of improvement suggestions for alternatives, with a performance profile incompatible with expectations. 


\section{Construction of the Performance Evaluation Model}

This section describes the use of the constructivist MCDA as an intervention instrument in the process of constructing the performance evaluation Therefore, this section discusses the stages of structuring, evaluation, and developing of recommendations.

\subsection{Structuring Stage}

The process of identifying the criteria (factors considered necessary and sufficient for the management of trade marketing) of decision maker's concern for a given context is still a creative and challenging one, but is improving, and in few years there will be some well-structured process also for this stage. Many techniques have been developed to identify the decision maker criteria (factors considered necessary and sufficient for the management of trade marketing) for a given context. Example are Eden (1988), Keeney (1992), Checkland and Scholes (1999), Hammond, Keeney and Raiffa (1999). All of them very useful, and, in this work, is presented the steeps proposed by Keeney (1992).

The main purpose, of identifying and understanding the meaning of the criteria (factors considered necessary and sufficient for the management of trade marketing), according to the decision maker's perception, is: first to improve focus in what is important; and second to have a scale to measure the performance of the actual situation and comparing it with other alternatives real or virtual and second to allow the generation of new opportunities. This process allows the decision maker(s) to increase his (their) knowledge and understanding of the problem taking on the control of the situation. Thus, the decision maker's participation is a prerequisite of the proposed approach.

Thus, even so the identification of criteria (factors considered necessary and sufficient for the management of trade marketing) is an art and requires hard thinking, there are some steps that when followed help and guide the process. According to Ensslin et al. (2001), this step are:

Step 0: Contextualize the problem identifying the actors and the participation of each one, mainly the decision maker (the actor(s) to whom the decision support model will be built), and the physical area involved;

Step 1: Write down all the concerns the decision maker hopes to address through the situation;

Step 2: Convert the decision maker concerns into succinct concerns (objectives oriented to action);

Step 3: Separate ends from means to establish the decision makers fundamental objectives, using cognitive mapping as proposed by Eden, (2004), Eden and Ackermann (2006);

Step 4: Clarify what the decision maker means by each objective, building the Hierarchy Tree of Objectives for the problem;

Step 5 : Build the ordinal scale that better represent the decision maker's concern in each criterion (objective) using the knowledge develop in the cognitive map;

Step 6: Identify and draw the profile of the actual context;

Step 7: Test the decision maker criterions (factors considered necessary and sufficient for the management of trade marketing) to see if they capture all the decision maker interest in the given context.

Applications of this procedure can be found in: De Moraes et al. (2010), Lacerda et al. (2011a), Lacerda et al. (2011b), Montibeller et al. (2008), Tasca et al. (2010), Della Bruna et al. (2011) and Rosa et al. (2012).

A first interview with the executives who requested decision aiding allowed the identification of the decision maker, of the stakeholders (interveners and facilitators) and of affected parties in the decision context. The directors established that the decision maker should be the trade marketing national coordinator of the subject pharmaceutical company. The national sales manager and national marketing manager of the company participated as interveners. The authors of this article acted as facilitators. Distributors, wholesalers, and retailers were characterised as affected parties in the decision aiding, i.e., parties who do not act in the decision, but are affected, directly or indirectly, by its results.

Three unstructured and open interviews were conducted with the decision maker and the interveners. The approximate duration of each interview was two hours. At the end of an interview, the map outline was submitted for the approval of the participants.

Once identified the decision makers the first step was, with the use of open interview techniques as proposed by Eden (2004), identify a main list of everything that the decision maker cares about in the decision context. What makes him happy as well as what makes him sad, in this context. The MCDA calls the elements of this list PEE- Primary Element of Evaluation. 
Next in order to improve the understanding of the elements of the list a new interview was done in order to organize the PEE and identify decision maker's perception about them. As a result the PEE were rewritten in an action oriented way and with the psychological opposite accepted by him (worst possible performance still accepted). The simple way of representing this evolution of the PEE is to use a verb at start of the phrase and the oppose is written after the ... and is read as "instead of". Each one of these action-oriented objectives is called a concern. The Table 1 shows some of decision maker's PEE - Primary Element of Evaluation and their corresponding concerns:

Table 1. Example of PEE and Their Corresponding Concerns

\begin{tabular}{ll}
\hline \multicolumn{1}{c}{ PEE } & \multicolumn{1}{c}{ Decision maker's concern } \\
\hline New costumer & $\begin{array}{l}\text { Identifying trade participation in the development of new costumer management } \\
\text { tools'... not taking participation into account. }\end{array}$ \\
Trade participation & $\begin{array}{l}\text { Determining trade participation in prospecting new business at retailers ... } \\
\text { ignoring the participation share of trade. }\end{array}$ \\
Campaigns for & $\begin{array}{l}\text { Establishing trade campaigns for retailers ... not taking this into account in trade } \\
\text { evaluation. }\end{array}$ \\
retailers & $\begin{array}{l}\text { Having performance measures of trade in joint actions with the marketing } \\
\text { dept. ...relegating to marketing the results of joints actions. }\end{array}$ \\
\hline
\end{tabular}

At this stage, the wish list of concerns was ready to be grouped in such a way to eliminate the redundancies and allow identification of the main objectives. In order to do this it is necessary to identify the means ends chain of each one. This was done with the use of cognitive maps as propose by Eden (2004), Eden et al. (2006); Montibeller et al. (2008). To construct the cognitive map was used the Decision Explorer (Brightman, 2002) software - a computational tool that assists in the graphical development of maps. Thus, it was possible to identify the concepts and their psychological opposites, to establish the direction of the influence relationships among them, and to group them into clusters (concerning areas important to the decision maker) interactively at the same time as the interviews (Eden, 2004; Eden et al., 2006; Montibeller et al., 2008).

Figure 1 shows a part of the cognitive map of the case study, in which the 'distribution' cluster is outlined:

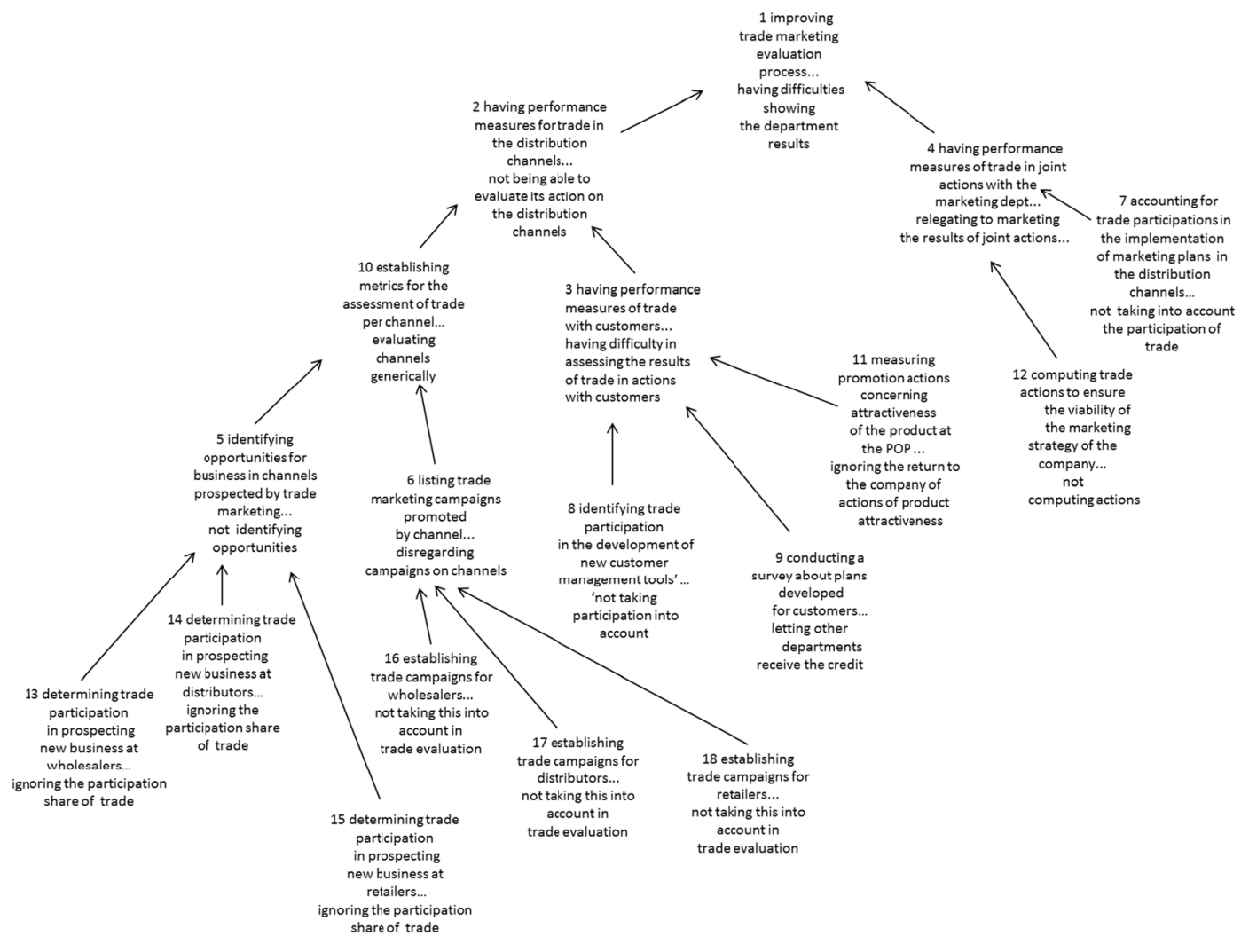

Figure 1. Part of the Cognitive Map for the Distribution Cluster 
In the next step of the structuring stage, the knowledge developed with the content of the above concepts and their influence on the relationships on the cognitive map, along with the concept of cluster, were used to identify areas and sub-areas of concern, allowing the creation of relationships and hierarchical structures.

The cognitive maps structure employs influence links between concepts. In these relationships, it is possible to have only one mean concept leading to one end concept or several mean concepts leading to an end concept. What is not possible is to have the same mean concept leading to more than one end concept. In such cases, it is evident that the mean concept contains more than one concern and, hence, the mean concept must be divided into its constituent parts so that, in the end, each mean concept will lead to an end concept (L. Ensslin, S. Ensslin, Rocha, Marafon, \& Medaglia, 2013).

On the other hand, the tree structures of multi-criteria models employ decomposition logic, wherein a complex criterion is decomposed into two or more criteria that implement its measurement. Hierarchically, a higher-level criterion should be explained by the set of lower-level criteria composing it. Furthermore, the criteria of a lower hierarchical level must be mutually exclusive and collectively provide an exhaustive characterisation of the hierarchically higher criterion (Ensslin et al., 2001; Keeney, 1992).

To perform the conversion, the framing technique of Keeney (1992) was used. It was implemented in four stages, all based on the analysis of clusters, which form the concern areas of the cognitive map in the case study. These phases are: 1) to determine where in the map the concepts that express ideas related to the strategic objectives of the decision makers are located; 2) to define where in the map the concepts that express ideas associated with potential actions available in the decision context are located; 3) to identify, in the map's hierarchical structure, those clusters of concepts that express ideas related to the decision makers' possible criteria candidates and to test them; and 4) to establish the hierarchical structure of the values of the decision-making process.

Keeney (1992) suggests that for a candidate to effectively become a criterion, an analysis of its properties should be conducted. In this examination, the criterion candidate must be essential, controllable, complete, measurable, operational, isolable, non-redundant, concise, and understandable within the decision context.

It was necessary to conduct three interviews with the decision aiding participants to carry out the four framing phases, the testing of possible criterion candidates of the model and the development of the hierarchical structure in its definitive form (Longaray et al., 2014).

Figure 2 shows the criteria tree of the model. At the top is the model label, 'Evaluating Trade Marketing Performance'. At the next hierarchical level are the areas of concern (Ai) 'Distribution', 'Market', and 'Sales'. The following level describes the model criteria (Ci): 'Partnerships', 'Logistic Operators', 'Retail', 'Volume Share', 'Revenue Share', 'Selling Out', and 'Customer Development'.

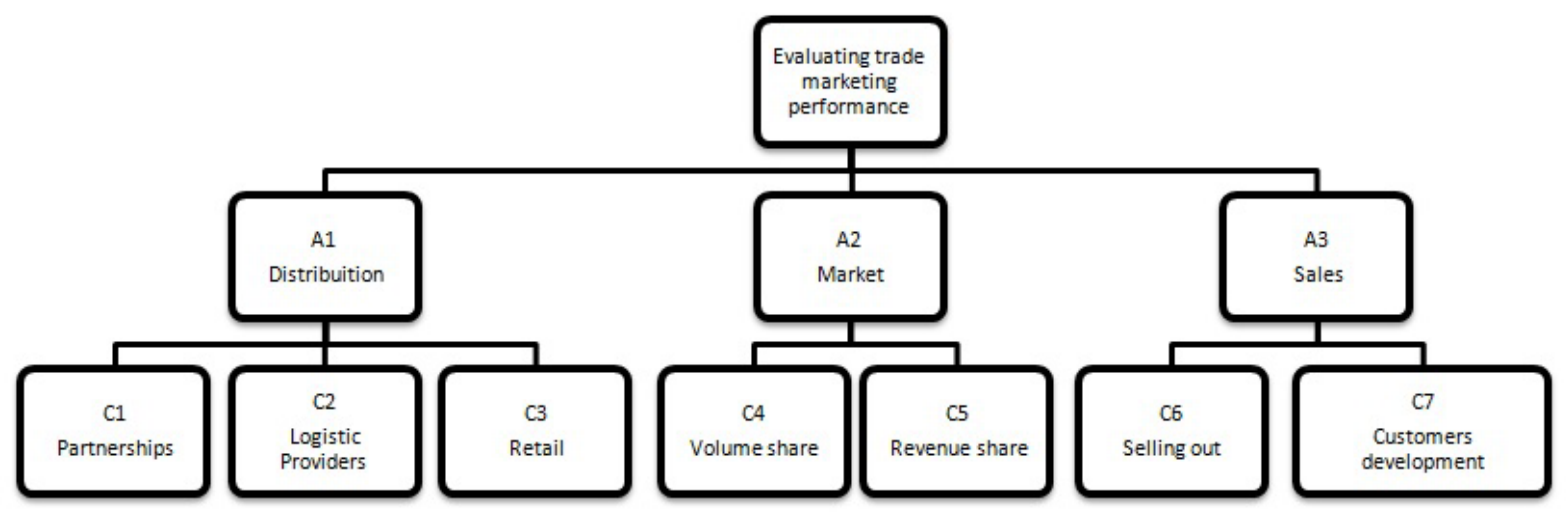

Figure 2. Hierarchical Structure of the Performance Evaluation Model of Trade Marketing from the Case Study in the

\section{Pharmaceutical Industry}

The last step of the structuring stage consisted of the construction of ordinal scales for each criterion of the model. Also called descriptors, ordinal scales are designed to allow possible alternatives to have their performance measured individually according to each criterion of the model.

Therefore, a descriptor has to have impact levels, ordered according to the preference perceived by the decision maker, 
in a pair-wise comparison process. (Ensslin et al, 2010). The level located at the lower end of the scale represents the worst performance and the level positioned at the upper end refers to the performance in which the performances at excellence level begin in the descriptor.

The decision maker must also point out the levels of neutral (performance below a level, which the decision maker considers compromising) and good (performance above a level, which the decision maker considers as excellence level) with regard to the criterion (Longaray et al, 2014).

In the current case study, the decision maker (trade marketing coordinator) monitored his preferences in the 28 descriptors identified for the performance evaluation model of trade marketing in the pharmaceutical industry.

Figure 3 presents, by way of illustration, the hierarchical structure of the model criteria with the expansion of the concern area 'distribution' of the model. It presents the unfolding of criterion C3 (retail) in sub-criteria C3.1 (attractiveness of the product), C3.2 (physical space), C3.3 (selling in), and C.4 (price strategy). At the lowest level of the structure, sub-criterion C3.1 is divided into three ordinal scales: D7-number of promotional activities by $\mathrm{POP} /$ month, D8 - number of multipliers by coverage area of POP/month, and D9-replacement cycle of products by $\mathrm{POP} /$ month. It is important to emphasise that the representations of levels were conducted using numbers that, in this case, are alphanumeric symbols and are not numbers from the set of real numbers. Therefore, the scales are ordinal.

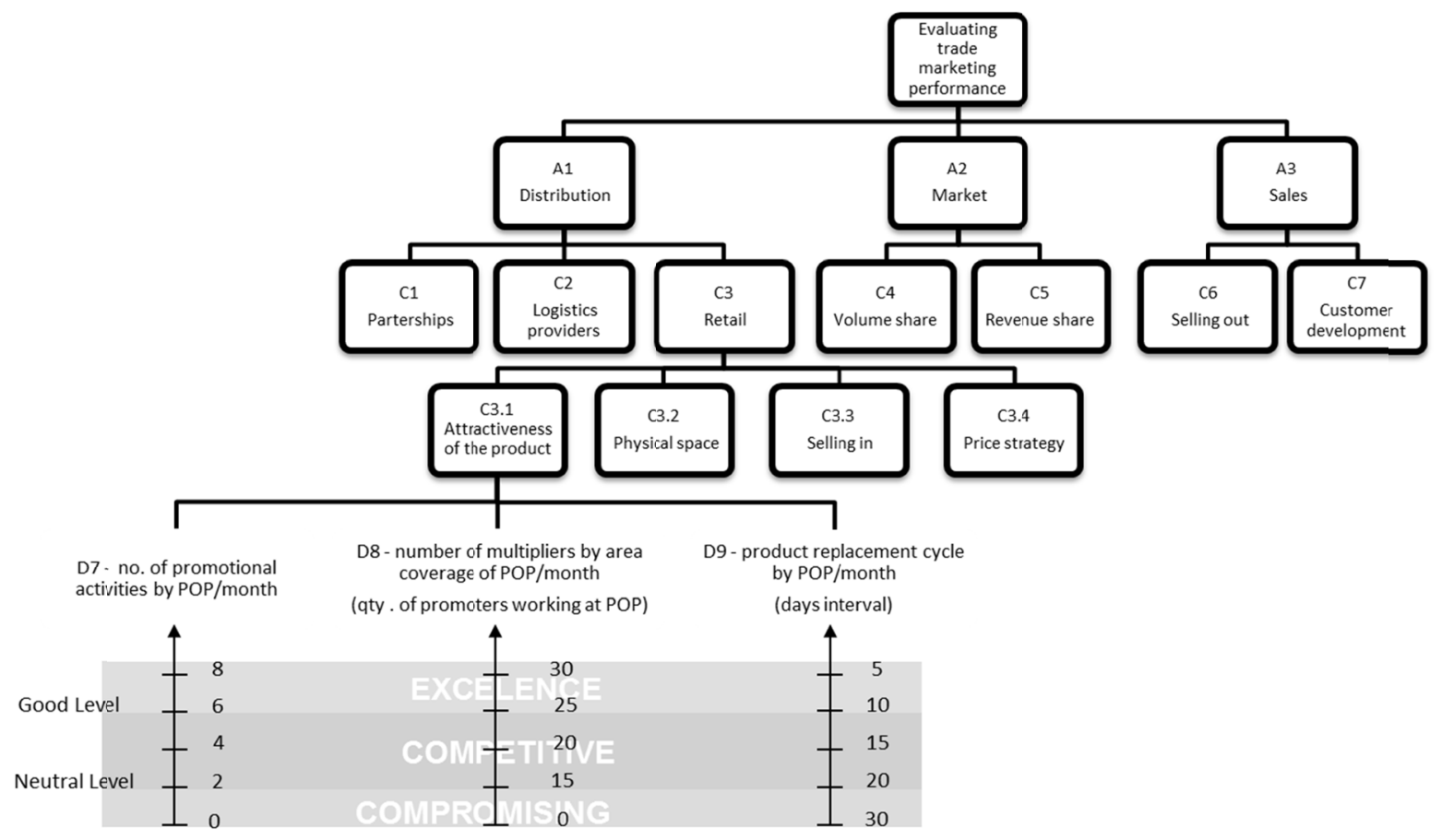

Figure 3. Ordinal Scales to Measure the Performance of a Possible Action in Sub-Criterion C3.1—Attractiveness of the Product

With the establishment of the descriptors for all criteria and sub-criteria of the model, the structuring phase of the process of decision aiding through constructivist MCDA was completed (Longaray et al, 2014). Thus, the attainment of the structuring stage provided knowledge of the decision context, the organisation and hierarchisation of the criteria, and the determination of the ordinal scales of the model. The model at this stage is qualitative and allows the understanding of what is important (factors considered necessary and sufficient for the management of trade marketing) and how to measure ordinally their performance. In order to improve the knowledge of the context is require to transform the ordinal scales into cardinal scale and aggregating the criteria in order to allow the overall performance measurement. This is the purpose of next section.

\subsection{Evaluation Stage}

In order to transform the ordinal model into a cardinal one is required new information about decision maker's preference. For this purpose this work uses the M-MACBETH software, guiding the decision maker in expressing preferences for construction of the value functions of the criteria and their rates of compensation, as well as the aggregation of all the criteria into a sole general criterion (Bana E Costa, De Corte \& Vansnick, 2005). 
At the first step of the evaluation stage, the value functions were established in each of the ordinal scales. For each value function, the decision maker expresses preference for a level of the scale compared to another level on the same scale. This measuring of preference intensity is called the difference of attractiveness and refers to the construction of a cardinal interval scale (Roy, 2010).

After the preliminary insertion of the description of all nominal scales with their levels of impact and of the anchorage of good and neutral levels in M-MACBETH, the researchers began the process of identifying the preferences of local attractiveness in the decision aiding model.

Three interviews were conducted with the decision maker in order to obtain the value functions of the 28 descriptors of the model. For example, for the matrix of semantic judgments D9 descriptor-replacement cycle of products by $\mathrm{POP} /$ month, the researchers asked the following types of questions of the decision-maker:

'Considering that certain potential action impacts on level N5 (...05 day interval for goods replenishment by POP), this level being the most attractive level, does passing then to level N4 (...10 day interval for the replenishment of goods by POP) seem to be a difference of attractiveness of indifferent, very weak, weak, moderate, strong, very strong, or extreme?'

In the case of the described judgement, in which the preference with regard to going from a replacement cycle of 05 days (excellent) to a 10-day replacement cycle (good) is compared, the decision maker's response was moderate.

The responses of the decision maker for the comparison of all scale levels allowed the complete filling of the semantic judgment matrix and the calculation of the value function anchored to descriptor D9-replacement cycle of product by $\mathrm{POP} / \mathrm{month}$, as shown in figure 4.

D9 - product replacement cycle by POP/month

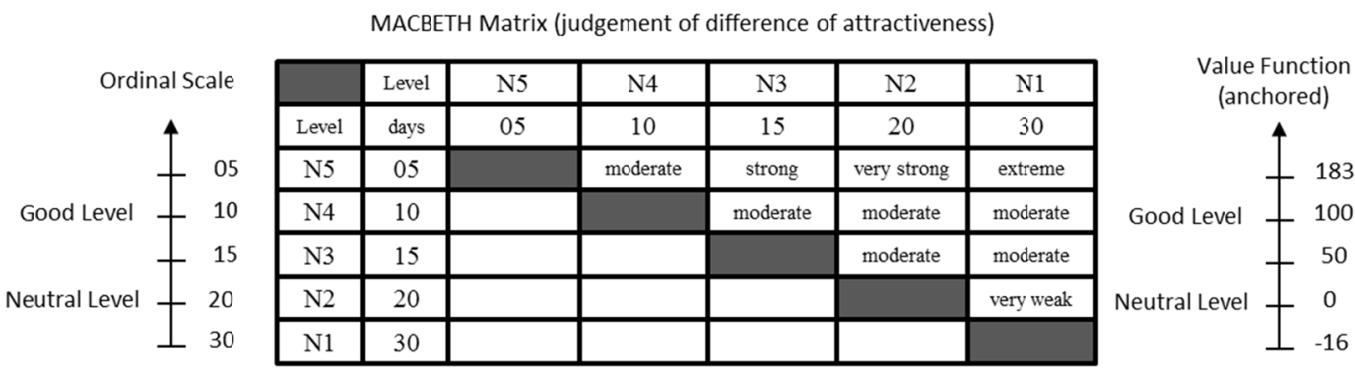

Figure 4. Value Function for Descriptor D9-Replacement Cycle of Products by POP/month

Analysis of Figure 4 verifies that the cardinal interval scale (value function) is normalised, i.e., the software has conducted a positive linear transformation of the $\mathrm{f}(\mathrm{x})=\alpha \mathrm{x}+\beta$ type to anchor neutral (0) and good (100) levels of the descriptor, and recalculated the other levels of the descriptor.

After the determination of value functions for all the descriptors, the next step establishes rates of compensation among the criteria of the model.

To this end, the MACBETH method is used to perform two procedures: a) creation of (Ai) actions that simulate the impact on good and neutral levels of the criteria to be judged and the ordering of these (creation of the ordinal scale) using the Roberts (1979) matrix; and, b) inclusion of a fictitious potential action in the judgement matrix (establishment of an A0 action necessary for the decision maker to evaluate the difference of attractiveness between passing from the good level to the neutral level regarding the least important criterion and to stay at the neutral level regarding all other criteria).

The rest of the procedure for the calculation of replacement rates follows the same premises described for value functions.

For this step, an interview lasting approximately three hours was conducted. In it, the decision maker expressed his judgments to obtain the replacement rates of the performance evaluation model of trade marketing activities for the pharmaceutical company in this case study. Figure 5 illustrates this process for criteria C1, C2, and C 3 of the model. 


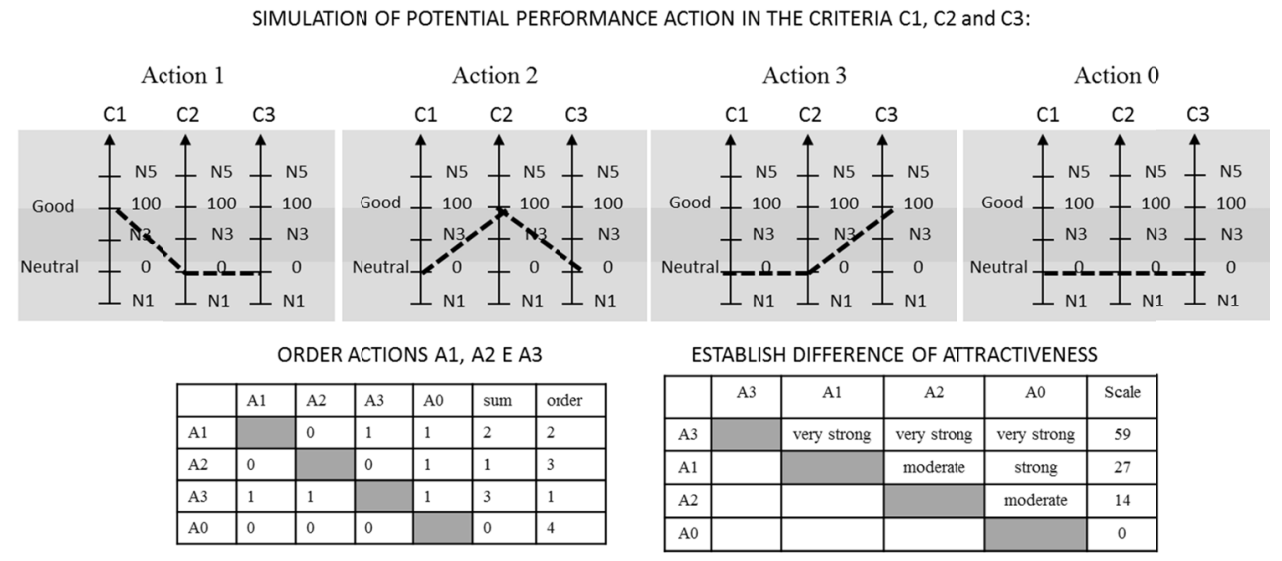

REPLACEMENT RATE AMONG THE CRITERIA C1, C2, AND C3 IN HIERARCHICAL STRUCTURE OF VALUES
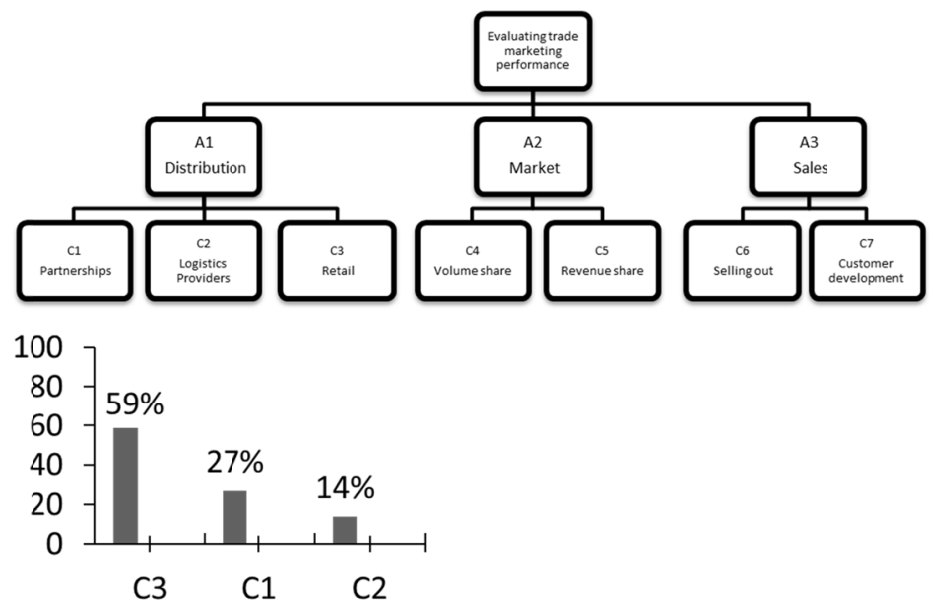

Figure 5. Process of Determination of Rates of Compensation among the Criteria $\mathrm{C} 1$-Partners, C2 - Logistics Providers, and C3-Retailers

The same procedure is used for the determination of all replacement rates among the criteria and sub-criteria of the criteria hierarchical structure.

The last step of the evaluation stage aggregates all the criteria of the model into a single general criterion, and is conducted in two phases (Bana E Costa, 1993).

In the first phase, the partial results of an action are aggregated into a single criterion (C) and their sub-criteria (i) using the Equation (1):

$V C_{k}(a)=\sum_{i=1}^{n k} w_{i, k} \cdot v_{i, k}(a)$

Where:

$\mathrm{VC}_{\mathrm{k}}(\mathrm{a})$ : global value of the action a from the point of view $\mathrm{C}_{\mathrm{k}}$, when $\mathrm{k}=1, \ldots \mathrm{m}$;

$v_{i, k}(a)$ : partial value of the action a at sub-criterion $i, i=1, \ldots n$, from $C_{k}$, when $k=1, \ldots$

$\mathrm{m}$;

a: level of impact of the action a;

$\mathrm{w}_{\mathrm{i}, \mathrm{k}}$ : replacement rate of the sub-criterion $\mathrm{i}, \mathrm{i}=1, \ldots \mathrm{n}$, from $\mathrm{C}_{\mathrm{k}}$, when $\mathrm{k}=1, \ldots \mathrm{m}$;

$\mathrm{n}_{\mathrm{k}}$ : number of sub-criteria of $\mathrm{C}_{\mathrm{k}}$, when $\mathrm{k}=1, \ldots \mathrm{m}$;

$\mathrm{m}$ : number of criteria of the model. 
Thus, using Equation (1), it is possible to obtain the aggregation formula for each area of concern A1 - distribution, A2 - Market and A3 - sales, of the hierarchical structure of values of the model, which are presented next:

\section{Vdistribution (a)}

$$
\begin{aligned}
& =0.27[0.44(0.34 v D 1(a)+0.66 v D 2(a))+0.56(0.32 v D 3(a)+0.68 v D 4(a))] \\
& +0.14(0.46 v D 5(a)+0.54 v D 6(a))+0.59\{0.42[(0.33 v D 7(a)+0.29 v D 8(a)+0.38 v D 9(a))] \\
& +0.21[(0.37 v D 10(a)+0.63 v D 11(a))] \\
& +0.18[(0.26 v D 12(a)+0.34 v D 13(a)+0.40 v D 14(a))] \\
& +0.19[0.55 v D 15(a)+0.45 v D 16(a)]\}
\end{aligned}
$$

Vmarket $(a)=0.64[0.52(0.37 v D 17(a)+0.63 v D 18(a))+0.48(0.43 v D 19(a)+0.57 v D 20(a))]$

$$
+0.36(0.30 v D 21(a)+0.34 v D 22(a)+0.36 v D 23(a))
$$

Vsales $(a)=0.55(0.41 v D 24(a)+0.59 v D 25(a))+0.45(0.47 v D 26(a)+0.23 v D 27(a)+0.30 v D 28(a)$

In the second step, the weighted sum of the partial values obtained is calculated using Equation (1). The weighting is conducted by applying the rates of compensation of each criterion in Equation (2):

$V(a)=\sum_{i}^{n} v_{i}(a) \cdot w_{i}$

Where:

$\mathrm{V}(\mathrm{a})$ : global value of the action a.

$v_{i}(a)$ : partial value of the action at the $i$-th criterion with $i=1,2, \ldots, n$.

$\mathrm{w}_{\mathrm{i}}$ Weight or Rate of compensation of the $\mathrm{i}$-th criterion with $\mathrm{i}=1,2, \ldots, \mathrm{n}$.

$\mathrm{n}$ : number of criteria of the model.

After the aggregation of the areas of concern, which incorporate the criteria, sub-criteria and descriptors of the model, it is possible to aggregate the performance of an action (a) in a single performance $\mathrm{V}$ (a) using the Equation (2):

$$
\operatorname{Vglobal}(a)=0.47 \text { distribution }(a)+0.34 \operatorname{Vmarket}(a)+0.19 \operatorname{Vsales}(a)
$$

Thus, the global formula of the decision aiding model to evaluate the trade marketing activities of the subject pharmaceutical company is obtained. The evaluation stage finishes with the completion of the construction of the multi-criteria model.

Now the cardinal model is completed allowing decision maker to visualize the performance profile of the trade marketing activities and the identification of the criteria(factors considered necessary and sufficient for the management of trade marketing) where it is weak, criteria where it is competitive and criteria where it has excellency performance. This knowledge allows the monitoring and the development of alternatives and strategies for improvements. This is the purpose of next section.

\subsection{Development of Recommendations Stage}

In constructivist MCDA the stage of development of recommendations aims to support the decision maker using the constructed multi-criteria model to monitor the overall performance and identify where are the opportunities to improve the performance of the context according with decision maker's values and preferences (Roy, 2010). It should be observed that the values of the decision maker were identified in structuring step and formed the basis for identifying the criteria and their ordinal scales as well as building the hierarchical structure of value (Figure 3). The criteria represent the factors considered necessary and sufficient for the management of trade marketing. This knowledge generates the qualitative model of evaluation. The decision maker's preferences were taken into account in the evaluation stage when the decision maker provided the information about the difference in attractiveness between the levels of the scales to build the functions and when it provided the difference in attractiveness between the contributions of the passage of the lower reference level to the higher reference level in each criterion when building the aggregation rate (Keeney, 1992). Therefore, the constructivist model MCDA in its first phase is qualitative and in the second phase is quantitative. This explains why often the complete constructivist MCDA model is framed as qualitative and quantitative one.

To start recommendation stage, Ensslin et al. (2010) suggest conducting an initial verification of the current 
performance (status quo) in order to identify in what aspects that the developed model is supposed to improve.

Figure 6 shows the performance profile of trade marketing activities identified by the decision maker after the evaluation stage.
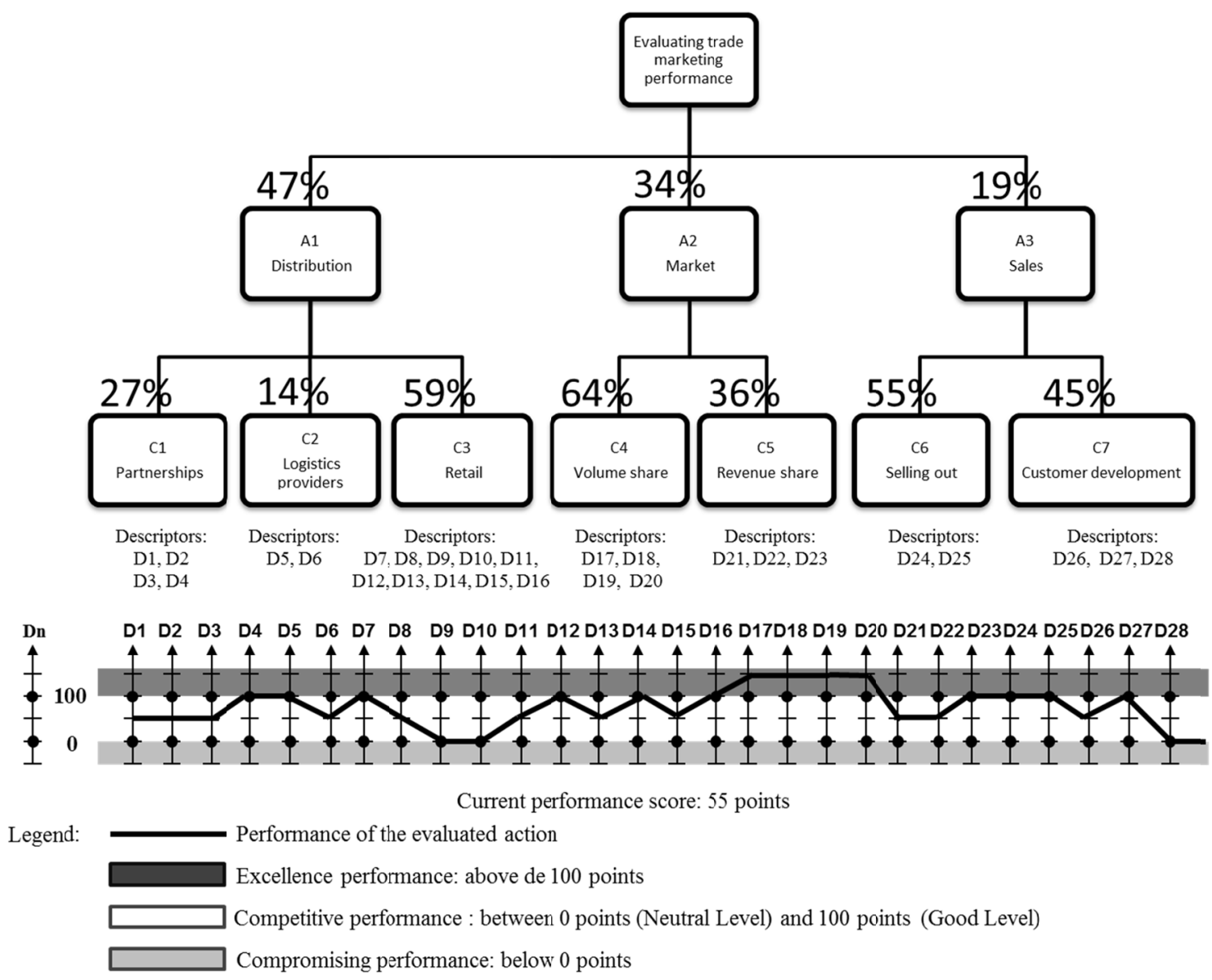

Figure 6. Performance Profile of Trade Marketing Activities in the Constructed Multi-Criteria Model

Figure 6 shows that by the time the evaluation was performed by the decision maker, only criterion C 5 -revenue share, had achieved excellent performance. Criteria $\mathrm{C} 1$-partnerships, $\mathrm{C} 2$ - logistic operators, $\mathrm{C} 4$ - volume share, and C6 - selling out had scores in the range of competitive performance. Conversely, criteria C3 - retail and C7-customer development showed performance at the compromising level on most of their descriptors. The global score of the evaluation was 55 points and is intended to serve as a comparison parameter with other possible performance profiles.

Based on the performance profile identified, the decision maker (trade marketing coordinator), and the interveners (national sales manager and national marketing manager), were considered the relevant persons to examine the causes of low performance of criterion $\mathrm{C} 3$-retail.

Viewing the vertical analysis of the hierarchical structure of values (Figure 6), shows that criterion C3 - retail is part of the area of concern A-distribution, which has a rate of compensation of $47 \%$, higher than the other areas of concern A2 - market (34\%) and A3 - sales (19\%). Among the criteria within the area of concern A1 - distribution, criterion C3 - retail has the highest rate of compensation (59\%). The other criteria, C1-partnerships and C2-logistics providers, have rates of $27 \%$ and $14 \%$, respectively.

Hence, it can be seen that criterion $\mathrm{C} 3$ - retail has the highest replacement rate among all the criteria belonging to area of concern $\mathrm{A} 1$, and that this area has the highest replacement rate among all areas of the multi-criteria model.

This allowed the decision maker and interveners to realise how much A1 and C3 are sensitive to variations of impact profiles in the model. 
In other analysis, the examination of the cardinal scales of criterion $\mathrm{C} 3$-retail, demonstrates that its poor performance can be explained by the physical factors represented by the descriptor D9-replacement cycle of products $\mathrm{POP} / \mathrm{month}$ and the descriptor D10 - numbers of participation as exhibitors at trade fairs. These descriptors have a performance in the status quo profile at the lowest acceptable level (neutral).

According to the trade marketing coordinator, a poor performance in the descriptor D9 can be explained by a policy adopted by the company in 2010, in which trade marketing promoters were promoted to sellers (change of department) without proper replacement. However, the less promotion of trade marketing there is, the lower the number of sales orders and, consequently, the lower the replacement cycle of products at the POP. This situation was revealed to the national sales manager in the meeting for the analysis of the performance profile, who confirmed not having noticed the negative impact of the new policy adopted and promised to take action.

Regarding descriptor D10, the company, which is 65 years old, does not usually participate in pharmacy trade fairs. Thus, the trade marketing coordinator referenced the results of the multi-criteria model to demonstrate to sales and marketing managers the importance of investing in the participation in fairs of the segment at the state and national levels.

As the stage of recommendations of constructivist MCDA is not prescriptive, other analyses can be conducted in the constructed multi-criteria model, such as the examination of the robustness of cardinal scales and the analysis of the sensitivity of rates of compensation.

\section{Summary}

This exploratory study aimed to support the decisions of the trade marketing manager by developing a model to evaluate the performance of a pharmaceutical company's trade marketing department activities. The nature of the study is characterised as a case study conducted at a large Brazilian pharmaceutical company, located in the state of Rio Grande do Sul, which operates in the segments of OTC medicines (over the counter), herbal medicines, cosmetics, and prescription medicines. As a source of data collection, unstructured interviews were conducted to obtain primary data, and a survey of documents and bibliographic search was conducted as a source of secondary data. The intervention instrument employed in the study was the Constructivist MCDA. This methodology for decision aiding was used due to its ability to provide conditions for the identification, implementation, and measurement of the criteria that represent the perception of the decision makers regarding the possibilities of evaluating the performance of trade marketing activities of the company. It also enabled the incorporation of improvement suggestions for alternatives with a performance profile incompatible with expectations.

The general objective of the study - constructing a customised model for evaluating the activities of the company's trade marketing - was achieved using Equation (2), which identified the global aggregation formula of the model for the evaluation of possible potential actions (alternatives).

The specific objectives were achieved while developing the model. In the structuring stage, the use of a cognitive mapping approach helped the actors view the context and identify aspects that met the evaluation goals of the company's trade marketing efforts. Keeney's (1992) framing enabled the transition from the map to the criteria hierarchical structure. After that, ordinal scales were constructed. At this stage, the qualitative model was ready to identify and measure ordinally the performance of the factors that decision maker considered necessary to evaluate the performance of the context. Although this be fundamental to the process of managing the context once it highlight what is important and how each factor is individually measured and what is the local performance of the context in this aspect, according with decision maker's perception, this qualitative model does not allow to have an holistic view of the context once it does not have the contributions of each criterion in the overall objective. In order to overcome this limitation the constructivist MCDA does the stage of evaluation whose purpose is the transformation of the ordinal scales of the model into cardinal scales and integrate all using a synthesis aggregation model.

In the evaluation stage, researchers used the MACBETH method to transform ordinal scales into cardinal scales, to establish rates of compensation among the criteria, and to construct the criteria aggregation model. Finally, at the recommendations stage, it was possible to represent the performance profile of the current situation (status quo) in the constructed model and to identify and analyse elements needing improvement.

The decision maker and interveners verified the multi-criteria model at all stages of its execution. At the end of its development, the decision maker obtained a formal tool to be used for performance evaluation of trade marketing activities, as well as a trading trick with regard to strategic issues within the scope of the directors and the company's board. 
As a theoretical contribution, the paper presents the ability to detail each step in the use of the constructivist MCDA. As a practical contribution, the research allowed the decision maker to participate in all phases of model development, which provided greater awareness of the complexities of the situation he was in, while, at the same time, legitimating the constructed model.

The limitations of the study were the time spent during interviews with the decision-maker and interveners, the need for involvement of the decision maker throughout the research process, and the singularity of the constructed model, which cannot be generalised. It is noteworthy that while the process can be replicated in other contexts, the developed model itself, since it was constructed to suit the specific conditions of the environment, cannot be used as constructed.

As a suggestion for future studies, the use of the constructivist MCDA is recommended for integrated evaluation of the performance of activities of trade marketing, marketing, and sales. Another possibility is the replication of this research in a different industrial segment. Finally, it is interesting that other elements of the pharmaceutical value chain, such as retailers or distributors, could evaluate trade marketing activities according to their perspectives.

\section{Acknowledgment}

The authors thank Editage.com for the translation of the text to English and to the anonymous reviewers for their important contributions to the work, as well as CNPq for funding the research.

\section{References}

Abradilan. (2013). Associação Brasileira dos Distribuidores de Laboratórios Nacionais. Retrieved October, 21, 2014 from http://www.abradilan.com.br/noticias_detalhe.asp?noticia $=7616 \mathrm{htm}$

Almeida, V., Penna, L., Silva, G., \& Freitas, F. (2012). Trade marketing no setor de lojas de conveniências. Revista de Administração de Empresas, 52(6), 643-656. http://dx.doi.org/10.1590/S0034-75902012000600006

Alvarez, F. J. (2008). Trade marketing: estratégias e aplicações. São Paulo: Saraiva.

Bana E Costa, C. A., De Corte, J. M., \& Vansnick, J. C. (2005). On the mathematical foundations of Macbeth. In: Greco, J., Ehrgott, S. (Ed.), Multicriteria Decision Analysis: state of the art survey (409-442). Boston: Springer Verlag.

Bana E., \& Costa, C. A. (1993). Três convicções fundamentais na prática do apoio à decisão. Pesquisa Operacional, $13,1-12$.

Bana E., Costa, C. A., \& Vansnick, J. C. (1995). Uma nova abordagem ao problema de construção de uma função de valor cardinal: Macbeth. Investigação Operacional, 15, 15-35.

Bana E., Costa, C. A., De Corte, J, M., \& Vansnick, J, C. (2012b). MACBETH. International Journal of Information Technology \& Decision Making, 11, 359-387. http://dx.doi.org/10.1142/S0219622012400068

Bana E., Costa, C., Lopez, R., \& Baets, B. (2012a). The MACBETH approach for multi-criteria evaluation of development projects on cross-cutting issues. Annals of Operations Research, 199(1), 393-408. http://dx.doi.org/10.1007/s10479-011-0877-4

Brightman, J. (2002). An introduction to Decision Explorer. New York: Banxia.

Castillo, J. D. (2000). Trade marketing. Madrid: Esic Editorial.

Checkland, P., \& Scholes, J. (1999). Soft Systems Methodology in Action: include a 30 years retrospective. Wiley: New York.

Cobra, M., \& Talarico, P. (2008). Trade marketing: conceitos \& aplicação. São Paulo: FGV.

De Moraes, L., Garcia, R., Ensslin, L., Da Conceição, M., \& De Carvalho, S. (2010). The multicriteria analysis for construction of bench markers to support the Clinical Engineering in the Healthcare Technology Management. European Journal of Operational Research, 200, 607-615. http://dx.doi.org/10.1016/j.ejor.2009.01.018

Della Bruna, E., Ensslin, L., \& Ensslin, S. R. (2011). Supply chain performance evaluation: a case study in a company of equipment for refrigeration. In Technology Management Conference (ITMC), 2011 IEEE International, 969-978.

Eden, C. (1988). Cognitive mapping. European Journal of Operational Research, 36, 1-13. http://dx.doi.org/10.1016/0377-2217(88)90002-1 
Eden, C. (2004). Analysing congnitive maps to help structure issues or problems. European Journal of Operational Research, 159, 673-686. http://dx.doi.org/10.1016/S0377-2217(03)00431-4

Eden, C., \& Ackermann, F. (2006). Where next for problem structuring methods? Journal of Operational Research Society, 57(7), 766-768. http://dx.doi.org/10.1057/palgrave.jors.2602090

Ensslin, L., Ensslin, S., Rocha, S., Marafon, A., \& Medaglia, T. (2013). Multi-criteria decision-aid constructivist model in the supplier evaluation process. Produção, 23(2), 402-421. http://dx.doi.org/10.1590/S0103-65132012005000065

Ensslin, L., Giffhorn, E., Ensslin, S., Petri, S., \& Vianna, W. (2010). Avaliação do desempenho de empresas terceirizadas com o uso da metodologia multicritério de apoio à decisão - construtivista. Pesquisa Operacional, $30(1), 125-152$.

Ensslin, L., Montibeller, G., \& Noronha S, M. (2001). Apoio à Decisão: Metodologias para Estruturação de Problemas e Avaliação Multicritério de Alternativas. Florianópolis: Insular. http://dx.doi.org/10.1590/S0101-74382010000100007

Galves, M., L. (2005). Structuring Decision Situations: a Brief Overview. In: Barthèlemy, J, P, Lenca, P. (Ed.), Advances in Multicriteria Decision Aid (32-40). Enst Bretagne, Brest.

Gil, A, C. (2002). Como elaborar projetos de pesquisa. São Paulo: Atlas.

Hammond, J., Keeney, R., \& Raiffa, H. (1999). Smart Choice: a practical guide to making better decisions. Harvard Busines Review Press.

Huber, M., Dippold, K, \& Forsthofer, R. (2012). Which factors drive product sales in OTC markets? International Journal of Pharmaceutical and Healthcare Marketing, 6(4), 291-309. http://dx.doi.org/10.1108/17506121211283208

IBGE. (2013). Indicadores da produção industrial por categorias de uso. Retrieved October, 21, 2013 from http://www.ibge.gov.br/home/presidencia/noticias/noticia_visualiza.php?id_noticia=1988\&id_pagina=1 htm

Keeney, R., L. (1992). Value-focused thinking: a path to creative decision making. London: Harvard University Press.

Kotler, P., Hermawan, K., \& Iwan, S. (2013). Marketing 3.0: as forças que estão definindo o novo marketing centrado no ser humano. Rio de Janeiro: Campus.

Labajo, V., \& Cuesta, P. (2004). El Trade marketing: búsqueda de un modelo de colaboración eficiente entre fabricantes y distribuidores. El punto de vista del fabricante. In: Anais del Encuentro de profesores universitarios de marketing, Alicante, Espanha.

Lacerda, R., T, Ensslin, L., \& Ensslin, S. (2011a). A Performance Measurement Framework in Portfolio Management: A Constructivist Case. Management Decision, 49, 1-15.

Lacerda, R., T., Ensslin, L., \& Ensslin, S. (2011b). A Performance Measurement View Of IT Project Management. The International Journal of Productivity and Performance Management, 60(2), 132-151. http://dx.doi.org/10.1108/17410401111101476

Longaray, A., Ensslin, L., \& Mackness, J. (2005). Problem structuring using Soft Systems Methodology and Multicriteria Decision aid Constructivist. Proceedings of fifth International Conference on Operational Research for Development (V ICORD). India: Kanpur Industrial and Management Engeneering Department, 109-114.

Longaray, A., Ensslin, L., \& Mackness, J. (2014). Multicriteria decision analysis to lead about messes problems: An illustrated case. Independent Journal of Management \& Production (IJM\&P), 5(3), 677-692. http://dx.doi.org/10.14807/ijmp.v5i3.143

Montibeller, G., Ackerman, F., Belton, V., \& Ensslin, L. (2001). Reasoning Maps for Decision Aid: A Methodology for Help Integrated Problem Structuring and Exploring of Decision Alternatives. In: ORP3, 2001, Paris. ORP3 2001. Paris: Lamsade, 1, 1-13.

Montibeller, G., Belton, V., Ackermann, F., \& Ensslin, L. (2008). Reasoning maps for decision aid: an integrated approach for problem-structuring and multi-criteria evaluation. Journal of the Operational Research Society, 59(5), 575-589. http://dx.doi.org/10.1057/palgrave.jors.2602347

Motta, R., Santos, N., \& Serralvo, F. (2008). Trade Marketing: teoria e prática para gerenciar os canais de distribuição. Rio de Janeiro: Campus. 
Roberts, F. (1979). Measurement Theory. In: Encyclopedia of Mathematics and Its Applications. New York: Addison-Wesley Publishing Company.

Rosa, F. S., Ensslin, S, R., Ensslin, L., \& Lunkes, R, J. (2012). Management environmental disclosure: a construtivist case. Management Decision, 50(6), 1117-1136. http://dx.doi.org/10.1108/00251741211238364

Rosenhead, J. (1989). Rational analysis for a problematic world: problems structuring methods for complexity, uncertainty, and conflict. Chichester: John Wiley and Sons.

Roy, B. (1996). Multicriteria Methodology for Decision Aiding. Dordrecht: Kluwer Academic Publishers. http://dx.doi.org/10.1007/978-1-4757-2500-1

Roy, B. (2005). Paradigms and challenges. In: Greco, J, \& Ehrgott, S. (Ed.), Multicriteria Decision Analysis: state of the art survey (03-24). Boston: Springer Verlag.

Roy, B. (2010). Robustness in operational research and decision aiding: A multi-faceted issue. European Journal of Operational Research, 200, 629-638. http://dx.doi.org/10.1016/j.ejor.2008.12.036

Silva Neto, Macedo-Soares, N., \& T, Pitassi, C. (2011). Adequação Estratégica das Áreas de Trade Marketing das Empresas de Bens de Consumo Atuando no Brasil. Revista ADM.MADE, 15(1), 01-22.

Sponton, A, C. (2008). A relação fornecedor-cliente: as boas alianças do trade marketing. In: Cobra, M, \& Talarico, P. (Ed), Trade marketing: conceitos \& aplicação (60-75). São Paulo: FGV.

Tasca, E., Ensslin, L., Ensslin, S., \& Alves, B. (2010). An approach for selecting a theoretical framework for the evaluation of training programs. Journal of European Industrial Training, 34(7), 631-655. http://dx.doi.org/10.1108/03090591011070761 